Article

\title{
Preparation and Characterization of Aminoglycoside-Loaded Chitosan/Tripolyphosphate/Alginate Microspheres against E. coli
}

\author{
Estefanía Tiburcio $^{1}$ (D), Eduardo García-Junceda ${ }^{1}$ (D), Leoncio Garrido ${ }^{2}$, Alfonso Fernández-Mayoralas ${ }^{1}$ (D), \\ Julia Revuelta ${ }^{1, *(D)}$ and Agatha Bastida ${ }^{1, *(D)}$
}

1 BioGlycoChem Group, Institute of General Organic Chemistry (CSIC), Juan de la Cierva 3, 28006 Madrid, Spain; tiburcio@uv.es (E.T.); eduardo.junceda@csic.es (E.G.-J.); alfonso.mayoralas@csic.es (A.F.-M.)

2 Nanohybrids and Interactive Polymers Group, Institute of Polymer Science and Technology (ICTP-CSIC), CSIC, Juan de la Cierva 3, 28006 Madrid, Spain; lgarrido@cetef.csic.es

* Correspondence: julia.revuelta@iqog.csic.es (J.R.); agatha.bastida@csic.es (A.B.); Tel.: +34-(91)-2587679 (J.R.); +34-(91) 5622900 (A.B.)

\section{check for}

updates

Citation: Tiburcio, E.;

García-Junceda, E.; Garrido, L.;

Fernández-Mayoralas, A.; Revuelta,

J.; Bastida, A. Preparation and

Characterization of

Aminoglycoside-Loaded

Chitosan/Tripolyphosphate/Alginate Microspheres against E. coli. Polymers 2021, 13, 3326. https://doi.org/

$10.3390 /$ polym 13193326

Academic Editor: Jalel Labidi

Received: 9 September 2021

Accepted: 25 September 2021

Published: 28 September 2021

Publisher's Note: MDPI stays neutral with regard to jurisdictional claims in published maps and institutional affiliations.

Copyright: (C) 2021 by the authors Licensee MDPI, Basel, Switzerland. This article is an open access article distributed under the terms and conditions of the Creative Commons Attribution (CC BY) license (https:// creativecommons.org/licenses/by/ $4.0 /)$.

\begin{abstract}
Although aminoglycosides are one of the common classes of antibiotics that have been widely used for treating infections caused by pathogenic bacteria, the evolution of bacterial resistance mechanisms and their inherent toxicity have diminished their applicability. Biocompatible carrier systems can help sustain and control the delivery of antibacterial compounds while reducing the chances of antibacterial resistance or accumulation in unwanted tissues. In this study, novel chitosan gel beads were synthesized by a double ionic co-crosslinking mechanism. Tripolyphosphate and alginate, a polysaccharide obtained from marine brown algae, were employed as ionic cross-linkers to prepare the chitosan-based networks of gel beads. The in vitro release of streptomycin and kanamycin A was bimodal; an initial burst release was observed followed by a diffusion mediated sustained release, based on a Fickian diffusion mechanism. Finally, in terms of antibacterial properties, the particles resulted in growth inhibition of Gram-negative (E. coli) bacteria.
\end{abstract}

Keywords: antibiotic delivery; chitosan particles; polysaccharide carriers; release kinetics; antibiotic activity

\section{Introduction}

Microbial infections have become a major problem in public health, and it has been anticipated that if no prior action is taken, these infections could lead to 10 million people dying every year by 2050 [1]. This threat is majorly due, on the one hand, to the increased emergence of drug-resistant microbes, which poses the serious risk of reversing previous medical progress in this field and bringing back many bacterial infections from the past. On the other hand, the development of new antibiotics has declined since 1980, which could be due to difficulties in clinical development and scientific, regulatory, and economic issues. In fact, in the past 20 years, only two new antibiotic classes have been approved by the FDA [2]. Based on these facts, the current studies are aimed towards the discovery of novel techniques to overcome these relevant changes, "re-employing" conventional antibacterial drugs $[3,4]$.

Drug delivery vehicles have been widely employed to encapsulate and deliver conventional antibiotics, improving their therapeutic index while minimizing their adverse effects [5-7]. These have shown unprecedented advantages such as enhancement of the effectiveness of existent antibiotics, by enhancing the physicochemical properties and stability of antibiotics and prolongation of antibiotic release, in addition to the capability of targeted delivery to the site of infection as an effective antimicrobial therapy [8-10]. 
Microspheres are of particular interest as antibacterial drug delivery systems, representing novel strategies of targeted drug delivery systems to alleviate the increasing resistance crisis [11]. Their large specific surface area favors the interaction with target tissues allowing the direct treatment application directly to tissues, rather than delivery via bodily fluids, keeping the antibiotic effectiveness even if a lower dose is administrated. In this sense, although both synthetic and natural polymers have been employed to obtain microspheres for controlled-release drug delivery [12-15], polysaccharide-based ones in their wide diversity have constituted an important research line in recent years, due to their diverse bioactive attributes as well as other functional properties (biocompatibility, stability, etc.) [16].

Chitosan (Ch) (Figure 1) is a sustainable polysaccharide derived from renewable feedstock which has many advantages, including good biocompatibility, strong biodegradable ability, mucoadhesive properties and low toxicity [17]. Consequently, Ch-based biomaterials are versatile scaffolds for drug delivery systems development due to their unique qualities [18]. Ch has a cationic nature due to the protonation of amino groups on the polymer backbone, allowing it to interact with anions [19]. The concept of polyelectrolyte complex (PEC) formation between oppositely charged polymers has been known and used for decades in different applications, including the development of spherical carriers for drug delivery. Thus, polymer-polymer cross-linking has been described as an interesting approach to obtain superior and biocompatible Ch hydrogels and has enabled the combination of $\mathrm{Ch}$ with other important biopolymers that can synergize to improve encapsulation efficiency, release and bioavailability [20].

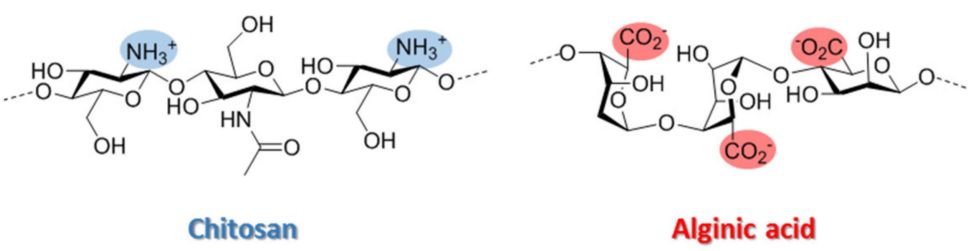

Figure 1. Chemical structures of chitosan and alginic acid.

Alginate (Alg) (Figure 1) is a commonly employed polysaccharide to form ChitAlg polyelectrolyte complexes (PECs). These materials have interesting properties, such as a good swelling behavior at different $\mathrm{pHs}$ and a better structural and mechanical stability than the isolated polymers. However, improving these properties remains a great challenge today.

Nowadays there is the question of how to improve the stability of Ch-based polyelectrolyte complexes during swelling in different media without losing their $\mathrm{pH}$-dependent swelling behavior. PECs can be reinforced through the formation of additional chemical cross-links between polyelectrolyte chains, being glutaraldehyde [21,22] the most common cross-linker used for $\mathrm{Ch} / \mathrm{Alg}$ complex reinforcement. However, this cross-linking agent may be associated with toxic and other undesirable effects of these particles that can limit their application, especially in biomedicine and pharmacy. Ionotropic gelation of chitosan by means of tripolyphosphate (TPP) represents a safe efficient alternative to covalent crosslinking because of milder condition of use and, in general, higher biocompatibility of the resulting systems. This reagent is by far the most employed cross-linker to ionically reticulate chitosan due to its high net negative charges (ranging from one to five depending on $\mathrm{pH}$ ) per monomeric unit and has successfully exploited to obtain chitosan nanoparticles and nano/micro-gels for drug delivery $[23,24]$.

In recent years, many techniques have been employed for chitosan particles preparation, being ionic gelation and polyelectrolyte complexation the most extensively employed for drug delivery. [25-27]. However, to date, there are very few studies focused on evaluating the antimicrobial effect provided by drugs such as aminoglycosides (AGAs) loaded in chitosan particles cross-linked with different polymeric anionic agents [20,28-30]. Due to the net positive charge caused by the amino groups in biological conditions, AGAs 
could be candidates for affinity-based encapsulation to create an antibacterial controlled release system.

These antibiotics are a family of critically important antibiotics for the treatment of serious infections [31]. However, their clinical use has been compromised by widespread instances of resistance [32] or adverse side effects such as ototoxicity and nephrotoxicity at high antibiotic doses [33], being the preparation of new aminoglycoside formulations that allow on-demand drug delivery a plausible solution to this sticky issue. Poly (lactic acid) or poly (lactic-co-glycolic acid)-based systems have been commonly employed for AGA encapsulation [34-36]; however, the formation of PLGA and PLA particles requires the use of organic solvents. This is a major drawback since, among other effects, the use of organic solvents can produce relevant toxicological effects and, moreover, can reduce the scalability and practical industrial application of these systems.

The goal of this study was to employ a polyionic complexation approach using chitosan and alginate/TPP to create particles in a single step by a simple mechanism, to provide a sustainable and efficient antibacterial platform with sustained and controlled release of AGAs, and subsequently demonstrate their antibacterial activity.

\section{Materials and Methods}

\subsection{Materials}

Chitosan (high molecular weight, batch STB06500; $\mathrm{M}_{\mathrm{W}}=310-375 \mathrm{kDa}, \mathrm{DD} \geq 75 \%$ ) and alginic acid (from brown algae, batch SLBQ3216V; $\mathrm{M}_{\mathrm{W}} \approx 240 \mathrm{kDa}, 61 \%$ of $\beta-(1 \rightarrow 4)$-Dmannosyluronic acid and 39\% of $\alpha(1 \rightarrow 4)$-L-gulosyluronic acid residues, approximately) were purchased from Sigma-Aldrich (Sigma-Aldrich, Saint Louis, MO, USA). Tripolyphosphate (TPP) was purchased from Alfa-Aesar (Alfa Aesar, Haverhill, MA, USA). Commercialgrade reagents were used without further purification. Centrifugations were performed with an Eppendorf centrifuge 5804R instrument (Eppendorf AG, Hamburg, Germany) at $4{ }^{\circ} \mathrm{C}$. The bacterial strain utilized in this study (E. coli BL21) was obtained from CECT (Spanish Type Culture Collection, Valencia, Spain).

\subsection{Preparation of Beads}

The AGA-loaded hydrogel beads were prepared using modifications of a previously described method [37] in three steps: polysaccharides dispersion (step 1), gel polymerization (step 2) and air-drying (step 3), according with the procedure presented in Figure 2.

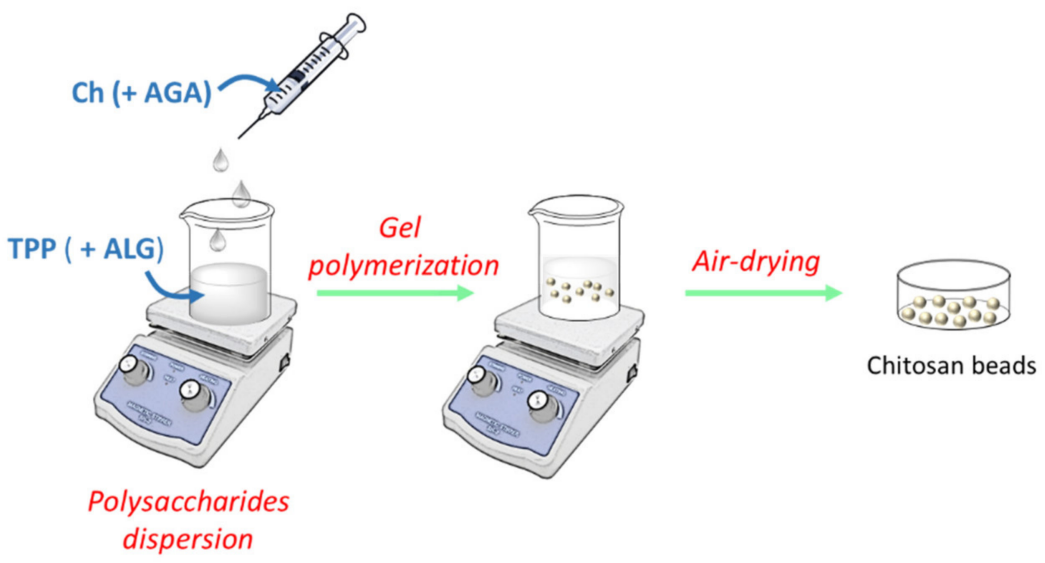

Figure 2. General flow chart of the preparation of chitosan-based beads.

\subsubsection{Step 1: Polysaccharides' Dispersion}

A chitosan dispersion $(1.7 \%(w / v)$ was prepared by adding the required amount of polymer in a $2 \%(v / v)$ solution of acetic acid under stirring. The system was left to stand for $24 \mathrm{~h}$ at room temperature for complete hydration of the polymer and removal of the bubbles, and subsequently, the $\mathrm{pH}$ of the solution was increased from 3 to 5 employing a 
1.0 $\mathrm{M} \mathrm{NaOH}$ solution, while the solution was mixed using vortex agitation for 2-3 min. For AGA inclusion, a solution of AGA $(\approx 50 \mathrm{mg})$ in water $(100 \mu \mathrm{L})$ was prepared and, next, was added slowly to $2 \mathrm{~mL}$ of the chitosan solution. In parallel, a solution of TPP $(3 \% w / v)$ and alginate $(2 \% w / v)$ in water was prepared. Both solutions were stirred until homogeneity.

\subsubsection{Step 2: Precipitation of Beads}

The chitosan/AGA solution ( $4 \mathrm{~mL}$ ) was dropped by using a syringe into $25 \mathrm{~mL}$ of cross-linking solution stirred with $300 \mathrm{rpm}$ on a magnetic stirred at room temperature. The beads were prepared by keeping them in the cross-linking solution under the static condition for $15 \mathrm{~min}$ at room temperature.

\subsubsection{Step 3: Air-Drying}

Finally, the beads were removed from the solution, were left to dry in a Petri dish for $24 \mathrm{~h}$ at room temperature, and then collected.

\subsection{Physico-Chemical Characterization}

Microspheres were characterized using previously described methods [38,39].

\subsubsection{FTIR Spectroscopy}

FT-IR spectra were recorded with $\mathrm{KBr}$ pellets on a One B Perkin-Elmer Spectrum spectrophotometer (Perkin-Elmer, Waltham, MA, USA). Fine powders of the samples were mixed with $\mathrm{KBr}$ powder in the ratio 1:100, and the mixture was subjected to a load of $10 \mathrm{ton} / \mathrm{cm}^{2}$ to produce a disc. Spectra were recorded in the absorbance mode in the range of 4000.0 and $400 \mathrm{~cm}^{-1}$ with a resolution of $4 \mathrm{~cm}^{-1}$.

\subsubsection{Microscopic Characterization}

Microscopic characterization of microspheres was done to investigate the morphology of particles by using a $2 \mathrm{MP}$ zoom stereo microscope (resolution $1600 \times 1200$, Tangxi, Chizhou, China). This microscopic evaluation was performed by using sediment after centrifugation of the microsphere suspension. The sediment was placed on object glass covered with a cover glass. Then, the observation was made using a $20 \times$ magnification lens.

\subsubsection{Scanning Electron Microscopy}

Shape and size of beads was analyzed by Scanning Electron Microscopy (SEM) at a bead concentration of $0.04 \mathrm{mg} / \mathrm{mL}$ using a Hitachi S-8000 (Hitachi, Tokyo, Japan) operating in transmission mode at $100 \mathrm{kV}$ on dry samples.

\subsubsection{Degree of Swelling}

The swelling rates of desiccated beads in a saline phosphate buffer solution $(50 \mathrm{mM}$, $\mathrm{pH}=7.4,100 \mathrm{mM} \mathrm{NaCl}$ ) were followed using a 2MP zoom stereo microscope (resolution $1600 \times 1200$, Tangxi, Chizhou, China). The degree of swelling was estimated as the ratio of the area of the projected surface of the particles [ø(d)], compared to that of freshly prepared swollen beads $[\varnothing(\mathrm{s})]$. The degree of swelling was therefore calculated according to:

$$
\text { Degree of swelling }(\%)=\frac{o(\mathrm{~s})-o(\mathrm{~d})}{o(\mathrm{~d})} \times 100
$$

\subsubsection{Degradation}

Dry microspheres with a diameter of $0.51 \mathrm{~mm}$ were immersed in PBS $(\mathrm{pH}=7.4)$ and the area of the projected surface of the particles $(\varnothing(\mathrm{mm}))$ was measured at different times.

\subsection{Antibiotic Activity}

The inhibition of bacterial growth by Chit/TPP/Alg microspheres charged with kanamycin and streptomycin was examined measuring zones of growth inhibition by the 
agar disk diffusion assay [40]. Briefly, a standardized inoculum of the microorganism (E. coli) is swabbed onto the surface of LB-agar plate, and then, AGA in solution as control or AGA microspheres were directly added onto the plate. After $24 \mathrm{~h}$ of culture in static conditions at $37^{\circ} \mathrm{C}$, the inhibition zone was analyzed. The normalized width of the antimicrobial "halo" [nw (halo)] of each disk was calculated according to:

$$
\mathrm{nw}(\text { halo })=\frac{\frac{d(i z)-d}{2}}{d}
$$

where $d(i z)$ is the outer diameter of the inhibition zone and $d$ the disk diameter.

\subsection{Drug Loading and Loading Efficiency}

The drug loading of the beads was estimated according to the agar disk-diffusion test. Briefly, $25 \mathrm{mg}$ of microspheres suspended in $200 \mu \mathrm{L}$ of saline PBS $(\mathrm{pH}=7.4)$ were placed in an Amicon Ultra 10K centrifugal filter and subject to centrifugation at $10,000 \times g$ for $10 \mathrm{~min}$ at room temperature. The filtrate was collected and loaded on foams placed later in contact with a pre-seeded of E. coli and the "halo" was measured after $24 \mathrm{~h}$ of culture in static conditions at $37^{\circ} \mathrm{C}$. Calibration curves were prepared by determination of antimicrobial "halo" of known antibiotics concentrations $(1 \mu \mathrm{g} / \mathrm{mL}, 10 \mu \mathrm{g} / \mathrm{mL}$ and $100 \mu \mathrm{g} / \mathrm{mL}$ ) in PBS. The drug loading and loading efficiency were calculated from the following equation, respectively:

$$
\begin{gathered}
\text { Drug loading }(\%, \mathrm{w} / \mathrm{w})=\frac{\text { Mass of drug in microspheres }}{\text { Mass of microspheres }} \times 100 \\
\text { Drug loading efficiency }(\%, \mathrm{w} / \mathrm{w})=\frac{\text { Drug loading }}{\text { Theorical drug loading }} \times 100
\end{gathered}
$$

\subsection{Cumulative Drug Release}

The release of drug from the microspheres was estimated in PBS $(\mathrm{pH}=7.4)$ at $37^{\circ} \mathrm{C}$ by agar disk-diffusion test. A volume of 200 microliters of the buffer solution was sampled periodically at predetermined intervals and was replaced with the same volume of fresh PBS (pH 7.4). The extracted aliquots were loaded on foams placed later in contact with a pre-seeded of E. coli BL21 agar plates according with the procedure described previously (Section 2.5). The amount of released antibiotic was calculated as cumulative percent release.

\subsection{Drug Release Kinetics}

Different models (zero order, first order, Higuchi square root of time, and HixsonCrowell models) were evaluated to understand the kinetics of drug release. [41]. The best fit was evaluated by calculating the correlation coefficient, according with the following equations, respectively:

$$
\begin{gathered}
F=K_{O} t \\
F=1-e^{-K_{1} t} \\
F=K_{H^{t}} t^{\frac{1}{2}} \\
\sqrt[3]{\bar{F}}=K_{S} t
\end{gathered}
$$

where $\mathrm{F}$ is the drug release fraction at time $\mathrm{t}(\mathrm{F}=\mathrm{Mt} / \mathrm{M} \infty)$ in which $\mathrm{Mt}$ is the drug-released percentage at time $t$ and $M \infty$ is the total drug-release percentage. Time has been normalized as $t / t \infty$ where $t \infty$ is the total experiment time.

Additionally, to understand the release mechanism, the release data were fitted to the Korsmeyer-Peppas model according to the following equation:

$$
\mathrm{F}=\mathrm{Kt}^{\mathrm{n}}
$$


The exponent " $n$ " is known as "diffusional exponent" and is related to the release mechanism, being obtained from the plot of $\ln (\mathrm{F})$ versus $\ln (\mathrm{t})$. When $n=0.5$, it is assumed that a Fickian diffusion occurs (diffusion-controlled transport), while a $n=0.5-1.0$ is associated to an anomalous or non-Fickian diffusion which is related with controlled swelling. [42,43].

\section{Results and Discussion}

\subsection{Preparation and Characterization of Chitosan Microspheres}

Supramolecular chitosan beads were generated via dropwise addition of an aqueous $\mathrm{Ch}$ or Ch/AGA solution into either TPP or TPP/alginate solutions through a 20-gauge syringe needle, equilibrating the resulting mixtures (which successfully formed millimeterscale spherical beads) at $25^{\circ} \mathrm{C}$ for at least $15 \mathrm{~min}$. Preliminary experiments were carried out in order to determinate the appropriate concentration range for chitosan, alginate and sodium tripolyphosphate, as well as other experimental conditions such as $\mathrm{pH}$ and polymers mass ratio. Modifications to the conditions were introduced along the optimization process to identify the best experimental conditions which were evaluated considering physical stability of microspheres suspensions (general aspect, formation of aggregates) and microspheres characteristics, such as size distribution. The obtained results indicated that the Ch/TPP microspheres are formed with better consistency when a 6:8 w/w TPP to chitosan mass ratio $(w / w)$ has been employed, while in the case of Ch/ / TPP/Alg ones, a 4:8:6 $w / w / w$ alginate to TPP to chitosan mass ratio $(w / w / w)$ gave the best results. In both cases, the procedure developed provided spherical beads of homogeneous surface with no tendency to aggregate (Figure $3 a, b)$.
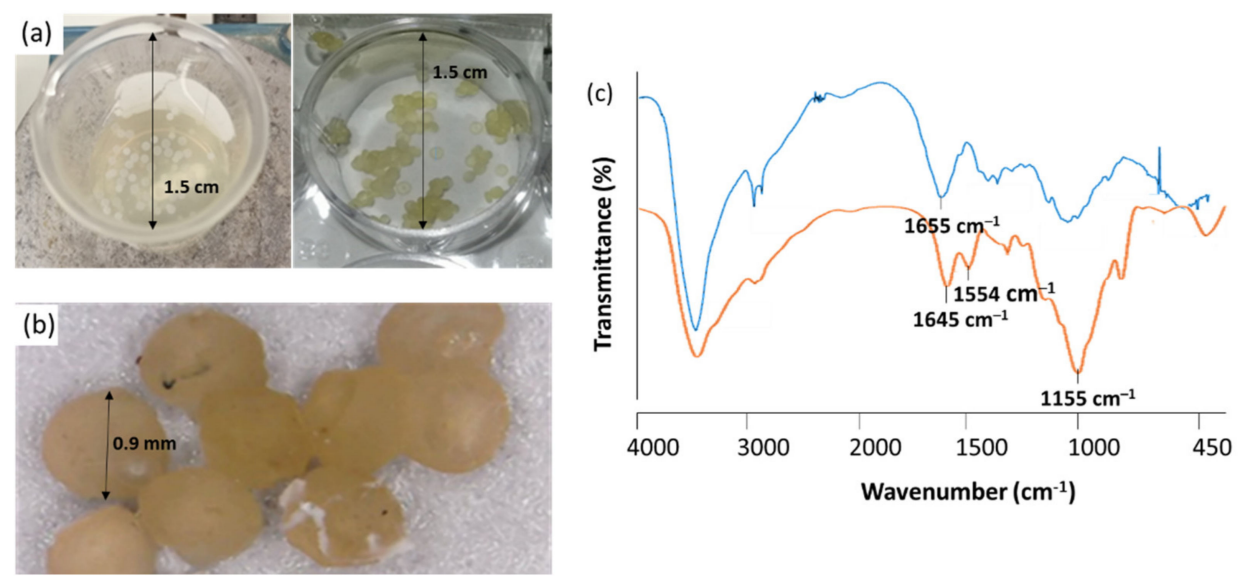

Figure 3. (a) Ch/TPP/Alg beads formation medium during Ch addition (left) and after precipitation (right); (b) microscopic view of microspheres sediment; (c) FTIR spectrum of Ch (blue) and Chitosan/TPP/Alg beads (orange).

FTIR spectroscopy was employed to identify the functional groups of the prepared beads. The FTIR spectra of chitosan and Chitosan/TPP/Alg are shown in Figure 3c. In FTIR spectrum of $\mathrm{Ch}$, the band at $1655 \mathrm{~cm}^{-1}$ is attributed to the $-\mathrm{NH}$ bending of the primary amine [44]. As can be observed in Figure 3c, this band disappears in the FTIR spectra of cross-linked chitosan, whereas two new peaks at $1645 \mathrm{~cm}^{-1}$ and $1554 \mathrm{~cm}^{-1}$ appear [45]. The disappearance of the band could be attributed to the complexation via electrolyte interactions between the negative ionic groups of TPP or Alg with $\mathrm{Ch}$. The cross-linked $\mathrm{Ch}$ also showed a peak for $\mathrm{P}=\mathrm{O}$ at $1155 \mathrm{~cm}^{-1}$ [46]. The adsorption of AGAs onto $\mathrm{Ch}$ beads did not show any significant additional peaks due to its similar functional groups that were overlapped in their peaks in the FTIR spectra of microspheres.

The morphology and sizes of microspheres were analyzed by Scanning Electron Microscopy (SEM). Results show that the average diameter of the Ch/TPP beads is about $600 \mu \mathrm{m}$ (Figure 4a), which is smaller than that obtained when Alg is introduced into the 
formulation, whose average diameter is about $900 \mu \mathrm{m}$ (Figure $4 \mathrm{~b}$ ). Furthermore, in the SEM micrographs, qualitative topographical differences can be observed between particles. In particular, the Ch/TPP system shows a flatter surface (Figure 4c) than the Ch/TPP/Alg, whose surface is much more granular (Figure $4 \mathrm{~d}$ ). This topographic change could be due to the incorporation of $\mathrm{Alg}$ and the consequent formation of PECs complexes by interaction between Alg's carboxylic groups and Ch's amines [47]. In addition, as can be observed in Figure 4e, the bead shapes are spherical and uniform in size.

(a)

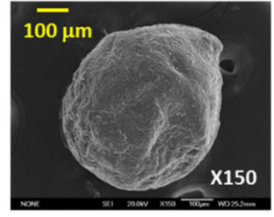

(b)

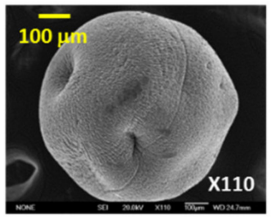

(c)

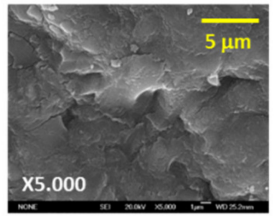

(d)

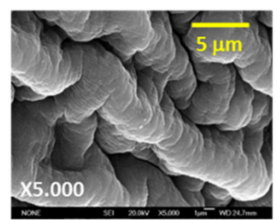

(e)

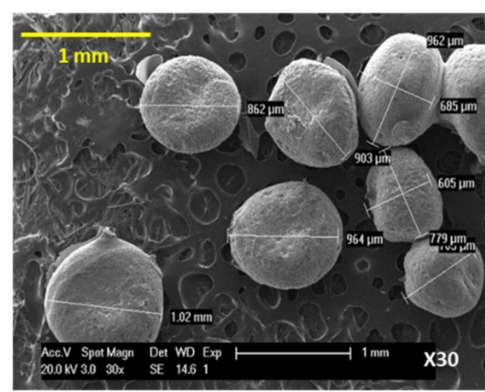

Figure 4. (a,b) Scanning electron microscope (SEM) image of Ch/TPP (a) and Ch/TPP/Alg beads (b); (c,d) Magnified view of Ch/TPP (c) and Ch/TPP/Alg beads (d); (e) Ch/TPP/Alg morphology.

In Figure 5 a graphical representation of the chemical structure of microspheres is showed. In both cases, TPP is present in the bulk of the microspheres bridging between positive charges of the chitosan chains [48]. When Alg is added, this binds chitosan on the surface of the microspheres, although a certain degree of diffusion in the bulk is possible.
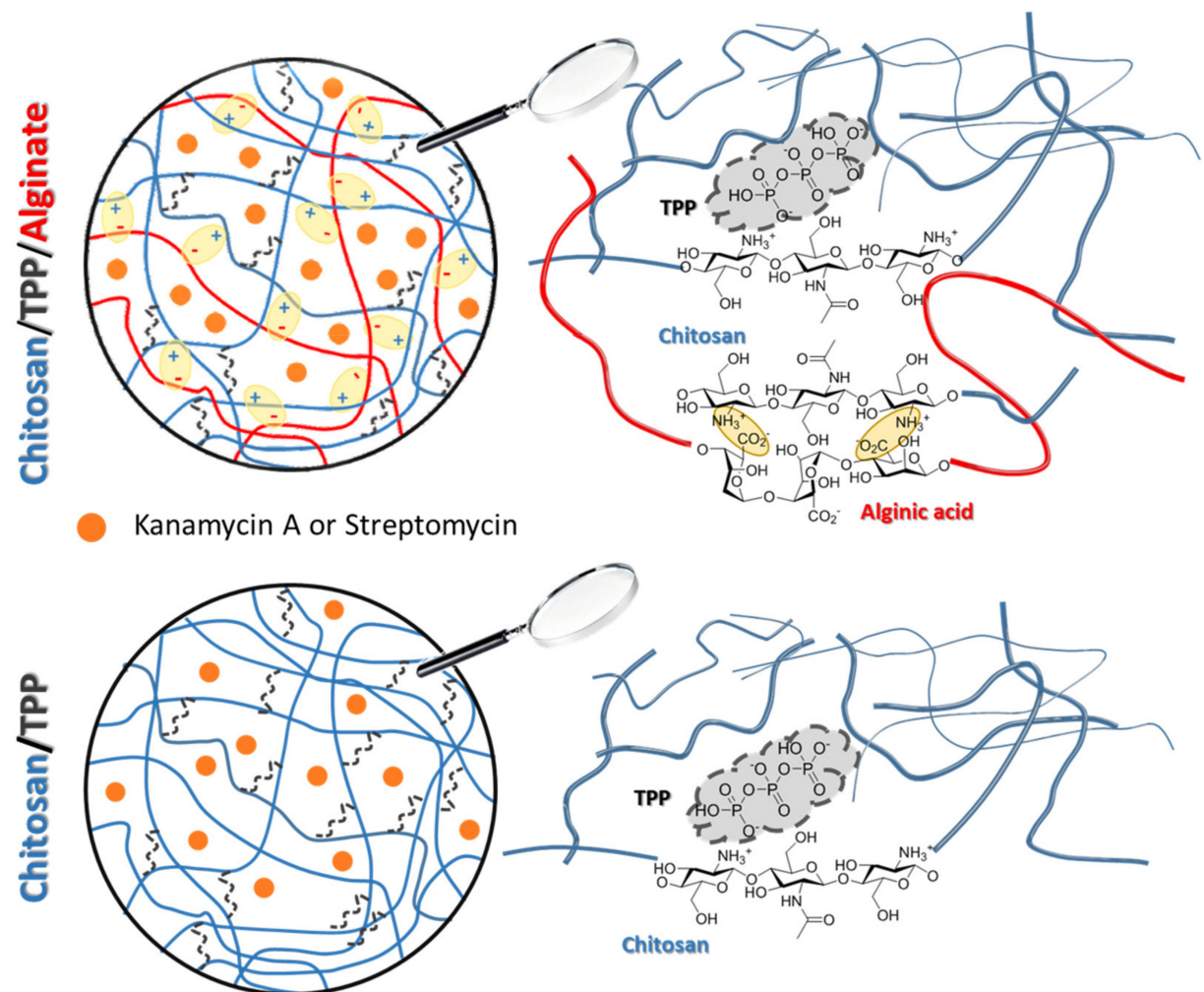

Figure 5. Graphical view of the Alg-coated chitosan/TPP and chitosan/TPP microspheres. 
Swelling of the developed particles was studied under physiological conditions (saline PBS, $\mathrm{pH}=7.4$ ), and the results are represented in Figure 6a. Ch/TPP microspheres showed higher percentage of water uptake $(\approx 52 \%)$ in comparison with $\mathrm{Ch} / \mathrm{TPP} / \mathrm{Alg}$ ones $(\approx 38 \%)$. This reduction in the water absorption capacity could be explained on the basis that the additional coating with alginic acid of the microsphere would form a dense ionic crosslinking on the surface of the bead that would act as a diffusion barrier, thus decreasing its capacity for water absorption. This barrier would be formed as a result of ionic interactions between carboxylic groups of alginic acid and chitosan amines. For all microspheres, the faster water uptake was observed during the first two hours, reaching a stable value after $5 \mathrm{~h}$, when equilibrium was attained. Finally, overall structural integrity of Ch/TPP/Alg microspheres was maintained in terms of form and size for at least two months, while $\mathrm{Ch} / \mathrm{TPP}$ ones suffered further degradation after a few days (Figure $6 \mathrm{~b}$ ). Therefore, the first formulation was selected as the best formulation to use for all subsequent experimentation.

(a)

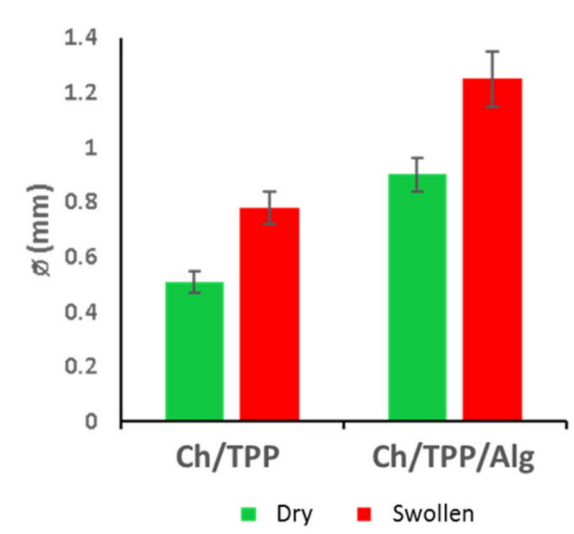

(b)

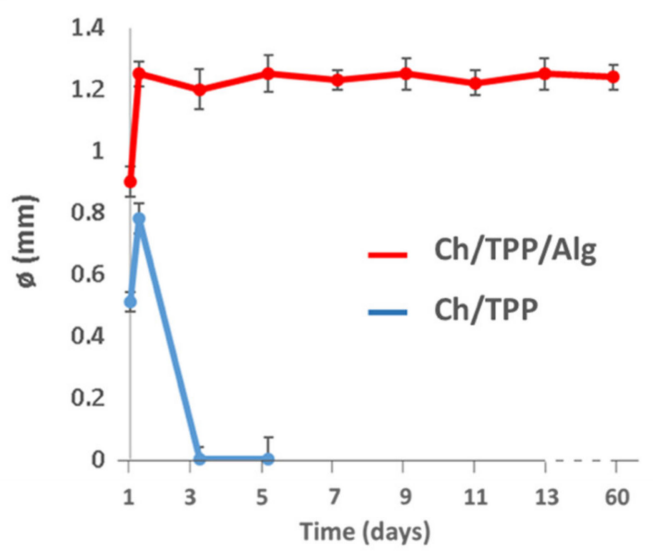

Figure 6. (a) Effect of microspheres composition on swelling after incubation in saline PBS ( $\mathrm{pH}=7.4$ ) for $5 \mathrm{~h}$. (b) Degradation of microspheres.

\subsection{Antibiotic Efficiency}

The first objective of our study was to identify the antimicrobial properties of microspheres. In order to assess the antimicrobial activity of microspheres, the zones of bacterial growth inhibition were measured for the streptomycin and kanamycin loaded, in comparison with that of free antibiotics (Figure 7a). Streptomycin and kanamycin A are powerful antibiotics with MICs of 5 and $4 \mu \mathrm{g} \mathrm{mL}^{-1}$, respectively, for the E. coli BL21 (DE3) strain $[49,50]$. The agar diffusion results showed that, after $24 \mathrm{~h}$, the AGA released from the beads was able to inhibit the bacterial growth of Gram-negative E. coli bacteria with a similar efficiency, or even better, in the case of kanamycin A, despite the amount of released-AGA, it should be significantly less than that of free-AGA. In addition, it has been observed that encapsulation of AGA prolonged its shelf life (at least 2 weeks). Thus, while free-AGAs showed strongest antibiotic activity for three days, the microspheres maintain this activity for a longer period (Figure $7 b$ ). 
(a)

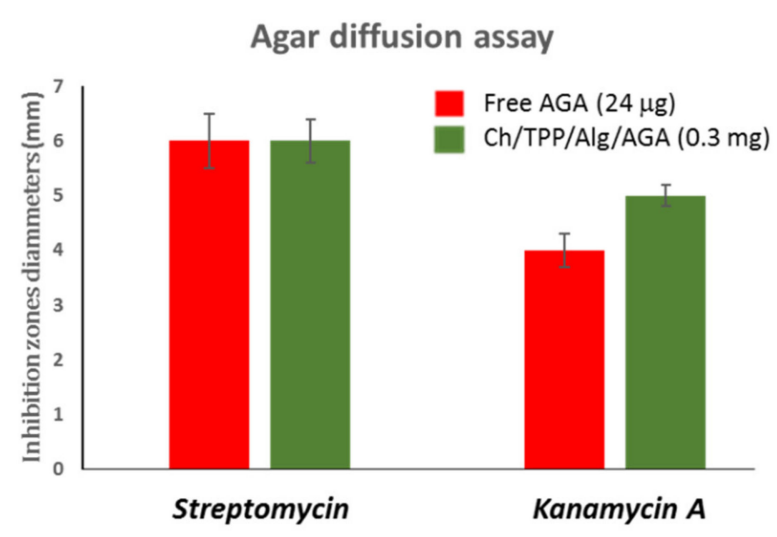

(b)

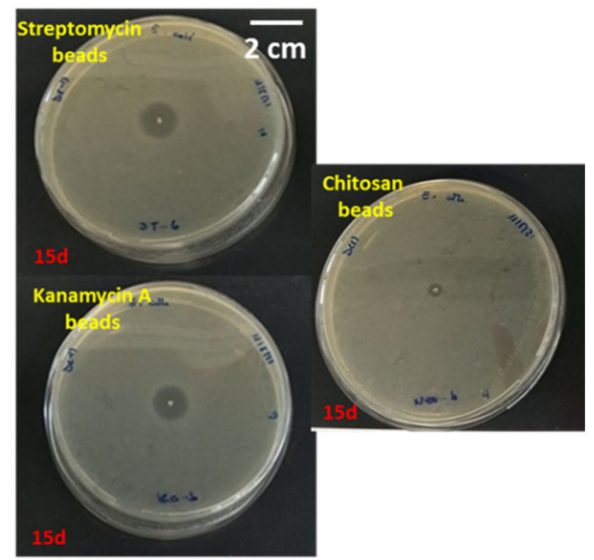

Figure 7. (a) Inhibition zone diameters (mm) of the free AGAs (red) and Ch/Alg/TPP/AGA (green) after $24 \mathrm{~h}$. Error bars represent the standard errors. (b) Antimicrobial agar-diffusion assay of microspheres after 15 days.

To go deeper into the antibiotic efficiency of microspheres, release kinetics of antibiotics from the Ch/TPP/Alg microspheres were measured (Figure 8a). AGAs absorb neither UV nor visible light. Hence, indirect analysis was performed to estimate the concentrations of the antibiotic, using aliquots antibiotic activity characterization by agar diffusion experiments (Figure $8 \mathrm{~b}$ ). The selection of this method has been based on the fact that the inhibition zone diameter increases proportionally with the antibiotic concentration [51].

(a)

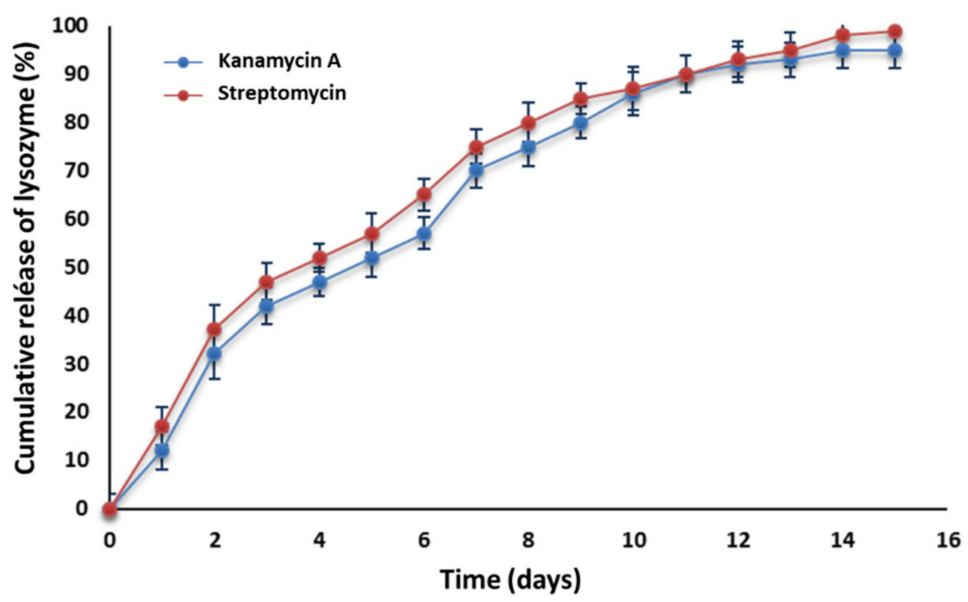

(b)

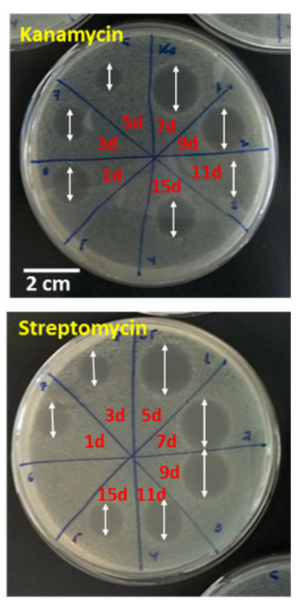

Figure 8. (a) In vitro release of kanamycin and streptomycin from the Ch/TPP/Alg microspheres. The mean cumulative concentration of antibiotic was expressed as a function of immersion time. (b) Examples of antibiotic release based on their antibacterial activity against E. coli BL21 (DE3) strain.

The in vitro studies were performed in $\mathrm{PBS}(\mathrm{pH}=7.4)$ at $37^{\circ} \mathrm{C}$, and the obtained cumulative percentage of drug release was plotted against time to obtain the drug release profile.

The relative faster antibiotic release during the first two days for both AGAs during the first three days (33.5\% for kanamycin and $38.1 \%$ for streptomycin) when compared with the slower sustainable release during the successive days of the experiment could be due to an initial easily released AGA that is attached to the Alg-surface of microspheres. In fact, other authors have recorded a total burst of gentamicin, another antibiotic of the AGA-family, released from Alg-hyluronic acid microspheres during the first hours [52]. They proposed that this initial burst release may have also been due to the release of gentamicin molecules that were adsorbed on the surface of microspheres. 
However, and despite the rapid initial release, if it is taken into account that the average drug loading efficiency was $8 \%$, the total AGA in $0.3 \mathrm{mg}$ of beads employed in the assay must be $24 \mu \mathrm{g}$, of which $3.8 \mu \mathrm{g}$ of streptomycin and $4.3 \mu \mathrm{g}$ of kanamycin A should be released in the first day of the experiment (see Figure 8a). According with these results, AGA-loaded beads prepared in this study have an increased antibacterial effect compared with the AGA solution again alone. This phenomenon could be due to a possible contribution of microspheres to the antibiotic activity. To analyze this possibility, we tested the antibacterial activities of Ch/TPP/Alg on E. coli. As shown in Figure 7b, Ch/TPP/Alg at an equal chitosan and alginate concentration to that in the loaded beads can inhibit the growth of E. coli. This indicates that, in addition to their role as carriers for antibiotics, microspheres contribute to the efficient antibacterial activity. These results are in agreement with those reported by other authors who found an increase in the inhibition ability of chitosan-alginate microspheres loaded with antibiotics in comparison with antibiotic alone, which confirms the antimicrobial potency of the microspheres [53-55]. Finally, to predict and correlate the release of AGAs from microspheres in vitro, results must be fit into a suitable mathematical model [41]. Among the different mechanisms known to control these processes, swelling, diffusion and erosion are the most accepted. In our study, we have used several conventional kinetic models, such as the zero-order, first-order, Higuchi and Hixon-Crowell ones. Table 1 shows the results of the kinetic modeling obtained for both antibiotics in our system.

Table 1. Kinetic release variables derived from mathematical models to describe AGA release from the microspheres.

\begin{tabular}{|c|c|c|c|c|}
\hline Mathematical Model & Constant & Value & Constant & Value \\
\hline & \multicolumn{2}{|c|}{ Kanamycin } & \multicolumn{2}{|c|}{ Streptomycin } \\
\hline \multirow{3}{*}{ Korsmeyer-Peppas } & $\mathrm{K}$ & 0.96 & $\mathrm{~K}$ & 1.00 \\
\hline & $\mathrm{R}^{2}$ & 0.982 & $\mathrm{R}^{2}$ & 0.970 \\
\hline & $\mathrm{n}$ & 0.62 & $\mathrm{n}$ & 0.60 \\
\hline \multirow[b]{2}{*}{ Zero-order } & $\mathrm{K}_{\mathrm{O}}$ & 0.83 & $\mathrm{~K}_{\mathrm{O}}$ & 0.81 \\
\hline & $\mathrm{R}^{2}$ & 0.955 & $\mathrm{R}^{2}$ & 0.918 \\
\hline \multirow[b]{2}{*}{ First-order } & $\mathrm{K}_{1}$ & 3.58 & $\mathrm{~K}_{1}$ & 4.20 \\
\hline & $\mathrm{R}^{2}$ & 0.937 & $\mathrm{R}^{2}$ & 0.898 \\
\hline \multirow{2}{*}{ Higuchi } & $\mathrm{K}_{\mathrm{H}}$ & 0.31 & $\mathrm{~K}_{\mathrm{H}}$ & 1.09 \\
\hline & $\mathrm{R}^{2}$ & 0.989 & $\mathrm{R}^{2}$ & 0.979 \\
\hline \multirow{2}{*}{ Hixon-Crowell } & $\mathrm{K}_{\mathrm{S}}$ & 0.58 & $\mathrm{~K}_{\mathrm{S}}$ & 0.38 \\
\hline & $\mathrm{R}^{2}$ & 0.951 & $\mathrm{R}^{2}$ & 0.821 \\
\hline
\end{tabular}

Starting with the Korsmeyer-Peppas model, we obtained a release exponent value $n$ of 0.62 for kanamycin and 0.60 for streptomycin, which is indicative of an anomalous release profile with a release mechanism controlled by both swelling and diffusion mechanisms (Figure 9). To further investigate whether diffusion or swelling was the governing mechanism of both antibiotics release out of the microspheres, other models have been applied (Table 1).

Among all the analyzed models, the Higuchi model showed the highest coefficient of determination (R2), which indicates that a Fickian diffusion mechanism governs the release of AGAs from the microspheres (Figure 9). According to this model, the release of antibiotics appears to be a predominantly diffusion-controlled process, so that the liquid penetrates the beads, dissolving the antibiotics found inside. 

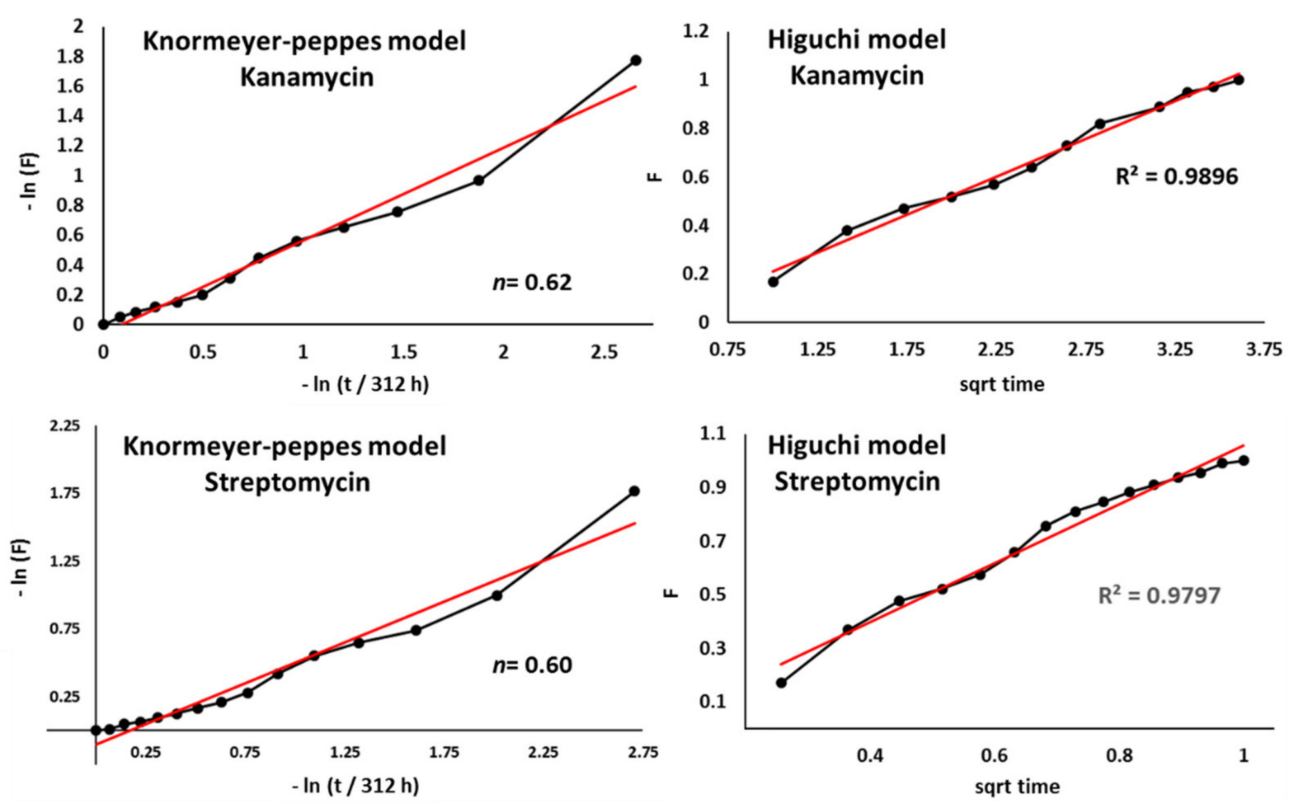

Figure 9. Drug release data fitted to Korsmeyer-Peppas and Higuchi models for kanamycin and streptomycin release (sqrt $=$ square root of time).

These data are in concordance with a fast release at the initial stage due to the water wake-up of the microspheres, followed by a slower release during the successive days of the experiment. It should be noted that although the Higuchi model satisfactorily explains our drug delivery system, a more detailed mathematical analysis would be necessary to obtain more definitive conclusions.

Thus, our findings suggest that $\mathrm{Ch} / \mathrm{TPP} / \mathrm{Alg}$ microspheres can be proposed as efficient carriers for aminoglycoside antibiotics that permit the initial fast antibiotic release, which exceeds the minimal antibiotic therapeutic concentration (1 to $4 \mu \mathrm{g} / \mathrm{mL}$ ) [56]. The present findings thus fit the initial need for high concentrations of antibiotic for infection treatments and avoid the sub-inhibitory antibiotic concentrations that can lead to a problematic resistance.

\section{Conclusions}

In this study, we report the synthesis and characterization of novel chitosan gel beads as a valuable platform for controlled release of the aminoglycosides streptomycin and kanamycin A. A double ionic co-crosslinking with TPP and alginate was used to prepare the chitosan-based networks of gel beads which were characterized in terms of their size, composition, and morphology. This particle formulation showed a sustained and controlled release of streptomycin and kanamycin based on a Fickian diffusion mechanism, which implies the solution of embedded antibiotics by liquid penetration inside the microsphere. Thus, during the first three days, a burst release was observed due to the fast water wake-up of the microspheres, whist in the next days, a slower diffusion mediated sustained release was observed for over 11 days. Moreover, these antibacterial particles were capable of effectively inhibiting E. coli strains' growth. This behavior could be replicated also against other Gram-negative bacteria.

In sum, the novel antibacterial particles provide a means for increasing drug viability and stability while reducing the chances of drug accumulation into non-targeted tissues taking advantage of their sustained release properties.

Author Contributions: Conceptualization, A.B. and J.R.; methodology, E.T. and L.G.; formal analysis, A.B. and J.R.; investigation, E.T. and A.B.; writing—original draft preparation, J.R.; writing-review and editing, A.F.-M., E.G.-J., A.B. and J.R.; supervision, A.B.; funding acquisition, A.F.-M. and J.R. All authors have read and agreed to the published version of the manuscript. 
Funding: This research was funded by Spanish AEI (MICINN) and FEDER (Project PID2019105337RB-C21).

Data Availability Statement: Not applicable.

Acknowledgments: The authors gratefully thank Jhazmine M. Morales and Raúl Benito for technical support.

Conflicts of Interest: The authors declare no conflict of interest.

\section{References}

1. O'Neill, J. Antimicrobial Resistance: Tackling a Crisis for the Health and Wealth of Nation; Review on Antimicrobial Resistance. 2014. Available online: http:/ / amr-review.org (accessed on 25 August 2021).

2. Luepke, K.H.; Suda, K.J.; Boucher, H.; Russo, R.L.; Bonney, M.W.; Hunt, T.D.; Mohr, J.F. Past, present, and future of antibacterial economics: Increasing bacterial resistance, limited antibiotic pipeline, and societal implications. Pharmacotherapy 2017, 37, 71-84. [CrossRef]

3. Zayyad, H.; Eliakim-Raz, N.; Leibovici, L.; Paul, M. Revival of old antibiotics: Needs, the state of evidence and expectations. Int. J. Antimicrob. Agents 2017, 49, 536-541. [CrossRef] [PubMed]

4. Bottger, E.C.; Crich, D. Aminoglycosides: Time for the Resurrection of a Neglected Class of Antibacterials? ACS Infect. Dis. 2020, 6, 168-172. [CrossRef] [PubMed]

5. $\quad$ Ferreira, M.; Ogren, M.; Dias, J.N.R.; Silva, M.; Gil, S.; Tavares, L.; Aires-da-Silva, F.; Gaspar, M.M.; Aguiar, S.I. Liposomes as Antibiotic Delivery Systems: A Promising Nanotechnological Strategy against Antimicrobial Resistance. Molecules 2021, 6, 2047. [CrossRef] [PubMed]

6. $\quad$ Rabiee, N.; Ahmadi, S.; Arab, Z.; Bagherzadeh, M.; Safarkhani, M.; Nasseri, B.; Rabiee, M.; Tahriri, M.; Webster, T.J.; Lobat Tayebi, L. Aptamer Hybrid Nanocomplexes as Targeting Components for Antibiotic/Gene Delivery Systems and Diagnostics: A Review. Int. J. Nanomed. 2020, 15, 4237-4256. [CrossRef]

7. Mela, I.; Kaminski, C.F. Nano-vehicles Give New Lease of Life to Existing Antimicrobials. Emerg. Top. Life Sci. 2020, 4, 555-566. [PubMed]

8. Giano, M.C.; Ibrahim, Z.; Medina, S.H.; Sarhane, K.A.; Christensen, J.M.; Yamada, Y.; Brandacher, G.; Schneider, J.P. Injectable Bioadhesive Hydrogels with Innate Antibacterial Properties. Nat. Commun. 2014, 5, 4095-4105. [CrossRef]

9. Li, W.; Dong, K.; Ren, J.; Qu, X. A $\beta$-lactamase-imprinted Responsive Hydrogel for the Treatment of Antibiotic-resistant Bacteria. Angew. Chem. Int. Ed. 2016, 55, 8049-8053. [CrossRef]

10. Zhang, Z.; He, T.; Yuan, M.; Shen, R.; Deng, L.; Yi, L.; Sun, Z.; Zhang, Y. The in Situ Synthesis of Ag/amino Acid Biopolymer Hydrogels as Mouldable Wound Dressings. Chem. Commun. 2015, 51, 15862-15865. [CrossRef]

11. Saini, S.; Kumar, S.; Choudhary, M.; Nitesh; Budhwar, V. Microspheres as Controlled Drug Delivery System: An Updated Review. Int. J. Pharm. Sci. Res. 2018, 5, 1760-1768.

12. Karp, F.; Satler, F.S.; Busatto, C.A.; Luna, J.A.; Estenoz, D.A.; Turino, L.N. Modulating Drug Release from Poly(lactic-co-glycolic) Acid Microparticles by the Addition of Alginate and Pectin. J. Appl. Polym. Sci. 2021, 138, e50293. [CrossRef]

13. Rotman, S.G.; Moriarty, T.F.; Nottelet, B.; Grijpma, D.W.; Eglin, D.; Guillaume, O. Poly(Aspartic Acid) Functionalized Poly(epsilonCaprolactone) Microspheres with Enhanced Hydroxyapatite Affinity as Bone Targeting Antibiotic Carriers. Pharmaceutics 2020, 12, 885. [CrossRef] [PubMed]

14. Wu, S.; Gong, Y.; Liu, S.; Pei, Y.; Luo, X. Functionalized Phosphorylated Cellulose Microspheres: Design, Characterization and Ciprofloxacin Loading and Releasing Properties. Carbohydr. Polym. 2021, 254, 117421-117429. [CrossRef] [PubMed]

15. Giacomello, E.; Sava, G.; Vita, F.; Delhom, N.; Mahl, P.; Bergamo, A. Chitosan-coated Alginate micro-particles Delivery of Active Principles Through Conventional Pelleted Food-A Study in Tilapia (Oreochromis niloticus). Int. J. Biol. Macromol. 2020, 165, 82-92. [CrossRef]

16. Luo, M.C.; Zhang, X.Y.; Wu, J.; Zhao, J.M. Modifications of Polysaccharide-based Biomaterials under Structure-Property Relationship for Biomedical Applications. Carbohydr. Polym. 2021, 266, 118097-118116. [CrossRef] [PubMed]

17. Riaz Rajoka, M.S.; Zhao, L.; Mehwish, H.M.; Wu, Y.; Mahmood, S. Chitosan and its Derivatives: Synthesis, Biotechnological Applications, and Future Challenges. Appl. Microbiol. Biotechnol. 2019, 103, 1557-1571. [CrossRef] [PubMed]

18. Takeshita, S.; Zhao, S.; Malfait, W.J.; Koebel, M.M. Chemistry of Chitosan Aerogels: Three-Dimensional Pore Control for Tailored Applications. Angew. Chem. Int. Ed. 2020, 59, 2-26.

19. Liang, Y.; Kiick, K.L. Heparin-functionalized Polymeric Biomaterials in Tissue Engineering and Drug Delivery Applications. Acta Biomater. 2014, 10, 1588-1600. [CrossRef]

20. Abri, S.; Amar, A.A.; Ress, G.; Barton, H.A.; Leipzig, N.D. Polyionic Complexed Antibacterial Heparin-Chitosan Particles for Antibiotic Delivery. ACS Appl. Bio. Mater. 2019, 2, 5848-5858. [CrossRef]

21. Wahba, M.I.; Hassan, M.E.; Ali, K.A. Chitosan-glutaraldehyde Activated Carrageenan-alginate Beads for Beta-D-galactosidase Covalent Immobilization. Biocatal. Biotransform. 2021, 39, 138-151. [CrossRef]

22. Gur, S.D.; Idil, N.; Aksoz, N. Optimization of Enzyme Co-Immobilization with Sodium Alginate and Glutaraldehyde-Activated Chitosan Beads. Biotechnol. Appl. Biochem. 2018, 184, 538-552. [CrossRef] 
23. Bugnicourt, L.; Ladaviere, C. Interests of Chitosan Nanoparticles Conically Cross-linked with Tripolyphosphate for Biomedical Applications. Prog. Polym. Sci. 2016, 60,1-17. [CrossRef]

24. Xu, J.; Xu, B.; Shou, D.; Xia, X.; Hu, Y. Preparation and Evaluation of Vancomycin-Loaded N-trimethyl Chitosan Nanoparticles. Polymers 2015, 7, 1850-1870. [CrossRef]

25. Lal, N.; Dubey, J.; Gaur, P.; Verma, N. Chitosan Based in Situ Forming Polyelectrolyte Complexes: A Potential Sustained Drug Delivery Polymeric Carrier for High Dose Drugs. Mater. Sci. Eng. C. 2017, 79, 491-498. [CrossRef] [PubMed]

26. Matalqah, S.M.; Aiedeh, K.; Nizar, M.M.; Alzoubi, K.H.; Bustanji, Y.; Hamad, I. Chitosan Nanoparticles as a Novel Drug Delivery System: A Review Article. Curr. Drug Targets 2020, 21, 1613-1624. [CrossRef] [PubMed]

27. Venkatesan, J.; Anil, S.; Kim, S.-K.; Shim, M.S. Chitosan as a Vehicle for Growth Factor Delivery: Various Preparations and their Applications in Bone Tissue Regeneration. Int. J. Biol. Macromol. 2017, 104, 1383-1397. [CrossRef] [PubMed]

28. Ciro, Y.; Rojas, J.; Oñate-Garzon, J.; Salamanca, C.H. Synthesis, Characterization and Biological Evaluation of Ampicillin-ChitosanPolyanion Nanoparticles Produced by Ionic Gelation and Polyelectrolyte Complexation Assisted by High-Intensity Sonication. Polymers 2019, 11, 1758. [CrossRef] [PubMed]

29. Spirescu, V.A.; Chircov, C.; Grumezescu, A.M.; Andronescu, E. Polymeric Nanoparticles for Antimicrobial Therapies: An up-to-date Overview. Polymers 2021, 13, 724. [CrossRef]

30. Ciro, Y.; Rojas, J.; Alhajj, M.J.; Carabili, G.A.; Salamanca, C.H. Production and Characterization of Chitosan-polyanion Nanoparticles by Polyelectrolyte Complexation Assisted by High-Intensity Sonication for the Modified Release of Methotrexate. Pharmaceuticals 2020, 13, 11. [CrossRef]

31. Santana, A.G.; Zárate, S.G.; Bastida, A.; Revuelta, J. Targeting RNA with aminoglycosides: Current improvements in their synthesis and biological activitiy. In Frontiers in Anti-Infective Drug Discovery; Atta-Ur-Rahman, F., Choudhray, M.I., Eds.; Bentham E-Books: Sharjah, United Arab Emirates, 2015; pp. 131-209.

32. Zárate, S.G.; De la Cruz, M.L.; Benito-Arenas, R.; Revuelta, J.; Santana, A.G.; Bastida, A. Overcoming Aminoglycoside Enzymatic Resistance: Design of Novel Antibiotics and Inhibitors. Molecules 2018, 23, 284. [CrossRef]

33. Jospe-Kaufman, M.; Siomin, L.; Fridman, M. The Relationship between the Structure and Toxicity of Aminoglycoside Antibiotics. Bioorg. Med. Chem. Lett. 2020, 30, 127218. [CrossRef]

34. Tyler, B.; Gullotti, D.; Mangraviti, A.; Utsuki, T.; Brem, H. Polylactic Acid (PLA) Controlled Delivery Carriers for Biomedical Applications. Adv. Drug Deliv. Rev. 2016, 107, 163-175. [CrossRef]

35. Vijayakrishna, K.; Patil, S.; Shaji, L.K.; Panicker, R.R. Gentamicin Loaded PLGA Based Biodegradable Material for Controlled Drug Delivery. ChemistrySelect 2019, 4, 8172-8177. [CrossRef]

36. Glinka, M.; Filatova, K.; Kucińska-Lipka, J.; Bergerova, E.D.; Wasik, A.; Sedlařík, V. Encapsulation of Amikacin into Microparticles Based on Low-Molecular-Weight Poly(lactic acid) and Poly(lactic acid-co-polyethylene glycol). Mol. Pharm. 2021, 18, 2986-2996. [CrossRef] [PubMed]

37. Vaziri, A.S.; Alemzadeh, I.; Vossoughi, M. Improving Survivability of Lactobacillus plantarumin Alginate-chitosan Beads Reinforced by Na-tripolyphosphate Dual Cross-linking. LWT-Food Sci. Technol. 2018, 97, 440-447. [CrossRef]

38. Gierszewska, M.; Ostrowska-Czubenko, J.; Chrzanowska, E. pH-responsive Chitosan/alginate Polyelectrolyte Complex Membranes Reinforced by Tripolyphosphate. Eur. Polym. J. 2018, 101, 282-290. [CrossRef]

39. Martins, A.F.; Bueno, P.V.A.; Almeida, E.A.M.S.; Rodrigues, F.H.A.; Rubira, A.F.; Muniz, E.C. Characterization of N-trimethyl chitosan/alginate complexes andcurcumin release. Int. J. Biol. Macromol. 2013, 57, 174-184. [CrossRef]

40. Tenover, F.C. Antibiotic susceptibility testing. In Encyclopedia of Microbiology, 3rd ed.; Schaechter, M., Ed.; Academic Press: Cambridge, MA, USA, 2009; pp. 67-77.

41. Mosselhy, D.A.; Ge, Y.; Gasik, M.; Nordström, K.; Natri, O.; Hannula, S.-P. Silica-Gentamicin Nanohybrids: Synthesis and Antimicrobial Action. Materials 2016, 9, 170. [CrossRef]

42. Korsmeyer, R.W.; Lustig, S.R.; Peppas, N.A. Solute and Penetrant Diffusion in Swellable polymers. I. Mathematical modeling. J. Polym. Sci. Part B Polym. Phys. 1986, 24, 395-408. [CrossRef]

43. Fu, Y.; Kao, W.J. Drug Release Kinetics and Transport Mechanisms of Non-degradable and Degradable Polymeric Delivery Systems. Expert Opin. Drug Deliv. 2010, 7, 429-444. [CrossRef]

44. Lin, Y.H.; Chang, C.H.; Wu, Y.S.; Hsu, Y.M.; Chiou, S.F.; Chen, Y.J. Development of pH-responsive Chitosan/heparin Nanoparticles for Stomach-specific Anti-Helicobacter pylori Therapy. Biomaterials 2009, 30, 3332-3342. [CrossRef]

45. Shahbazi, M.A.; Hamidi, M.; Mohammadi-Samani, S. Preparation, Optimization, and In-vitro/in-vivo/ex-vivo Characterization of Chitosan-heparin Nanoparticles: Drug-induced Gelation. J. Pharm. Pharmacol. 2013, 65, 1118-1133. [CrossRef]

46. Bhumkar, D.R.; Pokharkar, V. Studies on Effect of $\mathrm{pH}$ on Cross-linking of Chitosan with Sodium Tripolyphosphate: A Technical Note. AAPS PharmSciTech 2006, 7, 138-143. [CrossRef]

47. Kyzioł, A.; Mazgała, A.; Michna, J.; Regiel-Futyra, A.; Sebastian, V. Preparation and Characterization of Alginate/chitosan Formulations for Ciprofloxacin-controlled Delivery. J. Biomater. Appl. 2017, 32, 162-174. [CrossRef] [PubMed]

48. Nasti, A.; Zaki, N.M.; de Leonardis, P.; Ungphaiboon, S.; Sansongsak, P.; Rimoli, M.G.; Tirelli, N. Chitosan/TPP and Chitosan/TPPhyaluronic Acid Nanoparticles: Systematic Optimisation of the Preparative Process and Preliminary Biological Evaluation. Pharm. Res. 2009, 26, 1918-1930. [CrossRef] [PubMed] 
49. Latorre, M.; Peñalver, P.; Revuelta, J.; Asensio, J.L.; García-Junceda, E.; Bastida, A. Rescue of the Streptomycin Antibiotic Activity by Using Streptidine as a "Decoy Aceptor" for the Aminoglycoside-inactivating Enzyme Adenyl Transferase. Chem. Commun. 2007, 27, 2829-2831. [CrossRef] [PubMed]

50. Santana, A.G.; Zárate, S.G.; Asensio, J.L.; Revuelta, J.; Bastida, A. Selective Modification of the $3^{\prime \prime}$-amino Group of Kanamycin Prevents Significant Loss of Activity in Resistant Bacterial Strains. Org. Biomol. Chem. 2016, 14, 516-525. [CrossRef] [PubMed]

51. Bonev, B.; Hooper, J.; Parisot, J. Principles of Assessing Bacterial Susceptibility to Antibiotics Using the Agar Diffusion Method. J. Antimicrob. Chemother. 2008, 61, 1295-1301. [CrossRef]

52. Ratanavaraporn, J.; Chuma, N.; Kanokpanont, S.; Damrongsakkul, S. Beads Fabricated from Alginate, Hyaluronic Acid, and Gelatin Using Ionic Crosslinking and Layer-by-layer Coating Techniques for Controlled Release of Gentamicin. J. Appl. Polym. Sci. 2019, 136, 46893-46903. [CrossRef]

53. El-Ghannam, A.; Ahmed, K.; Omran, M. Nanoporous Delivery System to Treat Osteomyelitis and Regenerate Bone: Gentamicin Release Kinetics and Bactericidal Effect. J. Biomed. Res. Part B Appl. Biomater. 2005, 73B, 227-284. [CrossRef]

54. Thaya, R.; Vaseeharan, B.; Sivakamavalli, J.; Iswarya, A.; Govindarajan, M.; Alharbi, N.S.; Kadaikunnan, S.; Al-anbr, M.N.; Khaled, J.M.; Benelli, G. Synthesis of Chitosan-alginate Microspheres with High Antimicrobial and Antibiofilm Activity Against Multi-drug Resistant Microbial Pathogens. Microb. Pathog. 2018, 114, 17-24. [CrossRef] [PubMed]

55. Jin, J.; Xu, M.; Liu, Y.; Ji, Z.; Dai, K.; Zhang, L.; Wang, L.; Ye, F.; Chen, G.; Lv, Z. Alginate-based Composite Microspheres Coated by Berberine Simultaneously Improve Hemostatic and Antibacterial Efficacy. Colloids Surf. B 2020, 194, 111168-111178. [CrossRef] [PubMed]

56. Yadav, S.K.; Khan, G.; Bonde, G.V.; Bansal, M.; Mishra, B. Design, Optimization and Characterizations of Chitosan Fortified Calcium Alginate Microspheres for the Controlled Delivery of Dual Drugs. Artif. Cells Nanomed. Biotechnol. 2018, 46, 1180-1193. [CrossRef] [PubMed] 